\title{
Analytical Tool to Generate Torque-Speed Characteristics for Surface Mounted PM Machines in Constant Torque and Field Weakening Regions
}

\author{
M. Raza Khowja*, G. Vakil* and C. Gerada ${ }^{*+}$ \\ Power Electronics, Machine and Control (PEMC) Research Group \\ The University of Nottingham, $\mathrm{UK}^{*} \& \mathrm{CHINA}^{+}$ \\ Raza.Khowja@nottingham.ac.uk, Gaurang.Vakil@nottingham.ac.uk
}

\begin{abstract}
This paper presents an analytical tool to generate torque vs speed characteristics of the surface-mounted permanent magnet machines to minimize the computation time and efforts. The paper also derives an expression of $d$-axis current in the field weakening region while the stator resistance effect takes into account in order to evaluate the phase advance angles for the motor control. Finally, the results of the analytical tool have been compared with the MotorCAD software which gives less than $1 \%$ discrepancies in the results.
\end{abstract}

Keywords-PMSM, Constant torque region, Field weakening region, Analytical Tool and MotorCAD

\section{NOMENCLATURE}

$V_{d} \quad$ D-axis voltage

$V_{q} \quad$ Q-axis voltage

$\Psi_{m} \quad$ No-load flux linkage

$E \quad$ No-load voltage

$R_{S} \quad$ Stator phase resistance

$X_{d} \quad$ D-axis reactance

$X_{q} \quad$ Q-axis reactance

$L_{d} \quad$ D-axis inductance

$L_{q} \quad$ Q-axis inductance

$I_{S} \quad$ Stator current

$I_{d} \quad$ D-axis current

$I_{q} \quad$ Q-axis current

$\omega \quad$ Electrical speed in $\mathrm{rad} / \mathrm{s}$

$\omega_{\text {rad }} \quad$ Mechanical speed in $\mathrm{rad} / \mathrm{s}$

$P \quad$ Number of poles

$T_{e m} \quad$ Electromagnetic torque

$P_{\text {out }} \quad$ Output power

$\propto \quad$ Phase advance angle

\section{INTRODUCTION}

$\mathrm{P}$ ERMANENT MAGNET synchronous machines are known for their high-efficiency performance and high power density compared to their magnet-less synchronous counterparts [1]. They are the fast-growing motive elements in the industry. They are widely used in electric vehicle applications because of lower on-board power losses and heat generation thus imposing less stringent geometrical restrictions. The manufacturing process is relatively simple due to the absence of brushes (if compared with wound-field induction or de machines). The absence of brushes and commutator reduces maintenance cost as well as outage times. These machines allow construction with high pole number that makes them particularly suitable for directdrive applications [2-6].

Depending on the radial position of permanent magnets mounted on the rotor, these machines are classified into two main categories: surface-mounted permanent magnet synchronous machines and interior permanent magnet synchronous machines [7]. Surface-mounted permanent magnet synchronous motor is a direct descendent of permanent magnet dc motors as their 'inside out' with PMs mounted directly on the rotor. The stators of both categories are identical in construction that they contain balanced threephase windings $[2,4,5]$.

On the other hand, the rotor of an interior permanent magnet synchronous machine is constructed with magnets buried inside the ferromagnetic core thus the name 'interior permanent magnet'. Although it resembles a surface-mounted permanent magnet synchronous machine with regards to its construction, it exhibits markedly different characteristics in operation. The structure of its rotor makes them be classified as anisotropic or salient pole machines. The anisotropy is due to varying reluctance path provided by the rotor to a magnetic field surrounding it. The anisotropy or saliency plays a key role in determining the field-weakening operability of the motor $[4,5,8]$.

The design of permanent magnet motors requires a series of effort (using either simplified analytical model or finite element software's such as Infolytica MagNet or Motor-CAD) based on a given torque-speed requirements along with the volume and cooling constraints from machine design point of view and fundamental frequency restrictions from power electronics and control point of view [9]. This design process includes trial and error effort considering degrees of freedoms such as slot-pole combinations, winding configurations and geometrical dimensions, whilst satisfying the output power and strict volume requirements $[10,11]$.

Once the process of the machine design is completed the performance of it is then compared with the desired specification. If the specifications are satisfied the torquespeed characteristics curve along with the d-axis current vs rotor speed profile is required to control the machine in the field weakening region. In order to get these profiles, another trial and error effort is needed to generate these characteristic curves which consume a significant amount of time. Therefore, in this paper, analytical tool is developed for surface mounted PM machines to produce the torque, power and d-axis current vs speed profiles which reduces the computational time for the design engineer. The paper considers two cases while taking into account of stator resistive drop:

1) When the output power is held constant in the field weakening region. For this case, the supply current is increased to meet the constant output power requirement.

2) When the output power from the machine is not constant. In this case, the supply current is held constant in the field weakening region. 
In the next section, PMSM basics and its modelling are presented. In section IV, the expression for the d-axis current has been derived with and without stator resistive drop. Section $\mathrm{V}$ discusses the results from the analytical tool which is then compared with MotorCAD software to check the effectiveness of the tool. In the end, the paper is concluded in section VI.

\section{PMSM BASICS \& MODELLING}

The stator in a PMSM has three-phase sinusoidally distributed copper windings, while the rotor has PMs. With three-phase balanced sinusoidal currents in the three-phase stator windings, a sinusoidal magneto-motive force (MMF) is generated in the air gap. A sinusoidal distribution of rotor flux can be established by shaping the PMs and controlling their magnetization directions.

The electromagnetic torque is generated through an interaction of the stator and rotor magnetic fields [2, 12]. Due to the absence of the rotor winding the rotor currents are not present in this type of machine, therefore, the machine's electrical behaviour is completely described by the stator voltage equations. The steady-state $d q$ voltage equations in the synchronous reference frame for a three-phase non-salient pole SPMSM are given as,

$$
\begin{gathered}
V_{d}=R_{s} I_{d}+L_{d} \frac{d I_{d}}{d t}-L_{q} I_{q} \omega \\
V_{q}=R_{s} I_{q}+L_{q} \frac{d I_{q}}{d t}+I_{d} L_{d} \omega+\lambda_{m} \omega
\end{gathered}
$$
by

The steady-state stator phase voltage and current are given

$$
\begin{aligned}
& V_{s}=\sqrt{V_{q}{ }^{2}+V_{d}{ }^{2}} \\
& I_{s}=\sqrt{I_{q}{ }^{2}+I_{d}{ }^{2}}
\end{aligned}
$$

The electromagnetic torque developed by the permanent magnet synchronous machine is

$$
T_{e m}=3 \frac{P}{2} \lambda_{m} i_{q}+3 \frac{P}{2}\left(L_{d}-L_{q}\right) I_{d} I_{q}
$$

The surface-mounted PM machines develop the torque with the aid of magnet alignment only, therefore, (5) can be rewritten as

$$
T_{e m}=3 \frac{P}{2} \lambda_{m} I_{q}
$$

The expression of output power can be obtained from (6) as

$$
P_{\text {out }}=T_{\text {em }} \omega_{\text {rad }}
$$

Although the rotor's uniform cylindrical shape and uniform thickness of surface-mounted PM machines would theoretically give the same $L d$ and $L q$ and hence the machine saliency ratio of 1.0 , practically this is not always the case. Since the magnetic operating point for the ferromagnetic core used in the machine is set close to saturation during the design stage for reasons of obtaining maximum co-energy that translates to maximum energy conversion, the core saturation comes into play and modifies $L d$ and $L q$ unequally [3, 4]. Nevertheless, this difference between $L d$ and $L q$ in this type of machines is not significant and, hence, usually neglected for the analysis. In order to go into the field weakening region current advancing control is required once the motor terminal voltage has reached the available rated voltage to keep the motor voltage at its rated value as shown in Fig. 1. The $d q$ axis components of currents can be obtained as

$$
\begin{gathered}
I_{d}=-I_{s} \cos \propto \\
I_{q}=I_{s} \sin \propto
\end{gathered}
$$

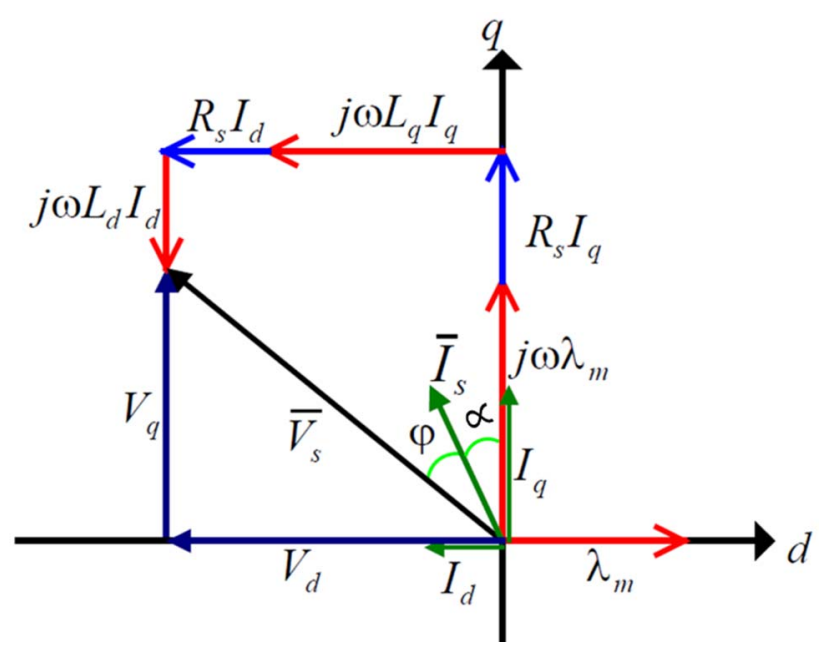

Fig. 1. Phase Diagram of PMSM with Field Weakening Mode

If $I_{d}$ is positive (i.e. When the phase advance angle $\alpha$ is negative or lagging), the stator current produces an MMF around the air gap that tends to aid the d-axis flux. If $I_{d}$ is negative the stator MMF is negative and causes demagnetization of the magnets. In this case, d-axis flux reduces as the $L_{d} \cdot I_{d}$ voltage drop opposes the PM flux in the opposite direction (Fig. 1). For positive or negative values of $\alpha$, the value of $i_{q}$ decreases for a constant stator current, and hence, the average torque also decreases.

\section{Analytical Model To Generate Torque, Power AND D-AXIS CURRENT VS SPEED CURVES}

In this section, the analytical tool to generate the torque, power and d-axis current vs speed characteristic curve is presented. The tool considers two cases while taking stator resistance drop into account:

1) It generates a torque-speed profile when the output power is held constant in the field weakening region. For this case, supply current can be increased to meet the constant output power requirement.

2) It generates a torque-speed profile when the output power from the machine is not constant. In this case, the stator current is held constant throughout the field weakening region.

The tool requires parameter as an input such as DC-link voltage, modulation index, the base speed at which motor voltage is reached to its rated value, maximum speed, output power (or output torque), pole number, no-load flux linkage, stator winding resistance and $d q$ axis inductance. These values are obtained using the software "Motor-CAD".

The tool is developed by obtaining the expression for $I_{d}$ from the phasor diagram of field weakening mode as shown in Fig. 1. Once the d-axis current is obtained, phase advance angles can be known using either (8) or (9). For both the aforementioned cases, in the constant torque region, $I_{d}$ is 
forced to zero whereas $I_{q}$ is obtained using (6) and (7) where $T_{e m}$ is given as an input parameter. The value of $I_{q}$ is also held constant since the output torque is unchanged in the constant torque region. The motor voltage (resistive drop neglected) in the constant torque region can be evaluated with the help of the phasor diagram (Fig. 1) as

$$
V_{s}=\sqrt{\left(E-X_{d} I_{d}\right)^{2}+\left(X_{q} I_{q}\right)^{2}}
$$

For case 1, in the field weakening region, the motor terminal voltage is held constant to its maximum allowable limit. The q-axis current is obtained from (6) and (7) whilst keeping the output power constant. In this case, in the field weakening region, the tool adjusts the q-axis current while limiting the motor voltage at its maximum allowable limit.

For case 2, in the field weakening region, the motor terminal voltage is also held constant to its maximum allowable limit. The stator current is given as a constant in the input parameters which is unchanged throughout the field weakening region. The q-axis current is then replaced using (4) in order to obtained d-axis current as:

$$
I_{q}=\sqrt{I_{s}{ }^{2}-I_{d}{ }^{2}}=\left(I_{s}{ }^{2}-I_{d}{ }^{2}\right)^{1 / 2}
$$

In order to expand $I_{q}$, it is required to apply binomial expansion theorem. By applying binomial expansion theorem on (11) we have,

$$
\begin{gathered}
(x+y)^{\frac{1}{n}}=x^{\frac{1}{n}}+\frac{\frac{1}{n}}{1 !} x^{\frac{1}{n}-1} y^{1}+\frac{\left(\frac{1}{n}\right)\left(\frac{1}{n}-1\right)}{2 !} x^{\frac{1}{n}-2} y^{2} \\
(x+y)^{\frac{1}{2}}=x^{\frac{1}{2}}+\frac{\frac{1}{2}}{1 !} x^{-\frac{1}{2}-1} y^{1}+\frac{\left(\frac{1}{2}\right)\left(\frac{1}{2}-1\right)}{2 !} x^{\frac{1}{2}-2} y^{2} \\
\therefore x=I_{s}{ }^{2} \text { and } y=-I_{d}{ }^{2} \\
\left(I_{s}{ }^{2}-I_{d}{ }^{2}\right)^{\frac{1}{2}}=I_{s}-\frac{1}{2} I_{s}{ }^{-1} I_{d}{ }^{2}-\frac{1}{8} I_{s}{ }^{-3} I_{d}{ }^{4} \\
\left(I_{s}{ }^{2}-I_{d}{ }^{2}\right)^{\frac{1}{2}} \approx I_{s}-\frac{1}{2} I_{s}{ }^{-1} I_{d}{ }^{2}=I_{q}
\end{gathered}
$$

The expression $\left(I_{s}{ }^{2}-I_{d}{ }^{2}\right)^{\frac{1}{2}}$ can be approximated to first two terms of the binomial expansion since the third term is divided by eight and will not make a big difference. For instance, $\mathrm{I}_{\mathrm{s}}=15 \mathrm{~A}$ and $\mathrm{I}_{\mathrm{d}}=5 \mathrm{~A}$ will give the $\mathrm{q}$-axis current of $14.14 \mathrm{~A}$ if (14) is used as opposed to q-axis current of $14.16 \mathrm{~A}$ if (15) is used.

\section{A. Id Expression for Constant Power Curve without Resistive Drop}

From (10), d-axis axis current by neglecting the resistive drop can be obtained as

$$
I_{d}=-\frac{1}{X_{d}}\left[\sqrt{V_{s}^{2}-\left(X_{q} I_{q}\right)^{2}}-E\right]
$$

B. Id Expression for Constant Power Curve with Resistive Drop

By adding the resistive drop terms to (10), the stator voltage is given as

$$
V_{s}^{2}=\left(E-X_{d} I_{d}+R_{s} I_{q}\right)^{2}+\left(X_{q} I_{q}+R_{s} I_{d}\right)^{2}
$$

By expanding (13) we have,

$$
\begin{gathered}
V_{s}^{2}=E^{2}-2 E\left(X_{d} I_{d}+R_{s} I_{q}\right)+\left(X_{d} I_{d}+R_{s} I_{q}\right)^{2}+X_{q}^{2} I_{q}^{2} \\
+2 X_{q} I_{q} I_{d} R_{s}+I_{d}^{2} R_{s}^{2} \\
0=E^{2}-2 E X_{d} I_{d}+2 E R_{s} I_{q}+X_{d}^{2} I_{d}^{2}+2 X_{d} I_{d} R_{s} I_{q}+R_{s}^{2} I_{q}^{2} \\
+X_{q}^{2} I_{q}^{2}+2 X_{q} I_{q} I_{d} R_{s}+I_{d}^{2} R_{s}^{2}-V_{s}^{2} \\
0=(19) \\
+\left(X_{d}^{2}+R_{s}^{2}\right) I_{d}^{2}+\left(-2 E X_{d}+2 X_{d} R_{s} I_{q}+2 X_{q} I_{q} R_{s}\right) I_{d} \\
\end{gathered}
$$

Equation (20) is a polynomial equation of degree 2 . Therefore, roots of (20) will give us the value of d-axis current in the field weakening the region and hence phase advance angles to generate a torque-speed profile.

\section{Id Expression for Constant Stator Current Curve without} Resistive Drop

In this case, the stator current is given as a constant in the input parameters which is unchanged throughout the field weakening region and the q-axis current is replaced with (11). Solving (10) for $I_{d}$ we have,

$$
\begin{gathered}
V_{s}^{2}=\left(E^{2}-2 E X_{d} I_{d}+I_{d}^{2} R_{s}^{2}\right)+\left(X_{q}^{2} I_{q}^{2}\right) \\
0=E^{2}-V_{s}^{2}-2 E X_{d} I_{d}+I_{d}^{2} R_{s}^{2}+X_{q}^{2} I_{q}^{2} \\
0=E^{2}-V_{s}^{2}-2 E X_{d} I_{d}+I_{d}^{2} R_{s}^{2}+X_{q}^{2}\left(I_{s}{ }^{2}-I_{d}{ }^{2}\right) \\
0=\left(X_{d}^{2}-X_{q}^{2}\right) I_{d}^{2}+\left(-2 E X_{d}\right) I_{d}+\left(E^{2}-V_{s}^{2}+X_{q}^{2} I_{s}^{2}\right)
\end{gathered}
$$

\section{Id Expression for Constant Stator Current Curve with Resistive Drop}

The d-axis current for constant stator current with a resistive drop can be obtained using (19).

$$
\begin{array}{r}
0=E^{2}-2 E X_{d} I_{d}+2 E R_{s} I_{q}+X_{d}^{2} I_{d}^{2}+2 X_{d} I_{d} R_{s} I_{q}+R_{s}^{2} I_{q}^{2} \\
+X_{q}^{2} I_{q}^{2}+2 X_{q} I_{q} I_{d} R_{s}+I_{d}^{2} R_{s}^{2}-V_{s}^{2}
\end{array}
$$

By substituting (15) in (25) we have

$$
\begin{aligned}
& 0=E^{2}-2 E X_{d} I_{d}+2 E R_{s}\left(I_{s}-\frac{1}{2} I_{s}{ }^{-1} I_{d}{ }^{2}\right)+X_{d}^{2} I_{d}^{2} \\
& +2 X_{d} I_{d} R_{s}\left(I_{s}-\frac{1}{2} I_{s}{ }^{-1} I_{d}{ }^{2}\right)+\left(R_{s}^{2}+X_{q}^{2}\right)\left(I_{s}{ }^{2}-I_{d}{ }^{2}\right)^{2} \\
& +2 X_{q} I_{d} R_{s}\left(I_{s}-\frac{1}{2} I_{s}{ }^{-1} I_{d}{ }^{2}\right)+I_{d}^{2} R_{s}^{2}-V_{s}{ }^{2}
\end{aligned}
$$

By converting (26) into a polynomial equation of degree 3 we have

$$
\begin{gathered}
\left(-\frac{X_{d} R_{s}}{I_{s}}-\frac{X_{q} R_{s}}{I_{s}}\right) I_{d}^{3}+\left(-\frac{E R_{s}}{I_{s}}+X_{d}^{2}-X_{q}^{2}\right) I_{d}^{2} \\
\quad+\left(-2 E X_{d}+2 X_{d} I_{s} R_{s}+2 X_{q} I_{s} R_{s}\right) I_{d} \\
+\left(E^{2}-V_{s}^{2}+2 E R_{s} I_{s}+R_{s}^{2} I_{s}^{2}+X_{q}^{2} I_{s}^{2}\right)=0
\end{gathered}
$$

Equation (27) is a polynomial equation of degree 3 . Therefore, the roots of (27) will give us the value of d-axis current in the field weakening region when stator resistive drop has been considered. 


\section{RESUlts AND DiscUSSION}

For the purpose of validation, two machines have been considered to compare the results of an analytical tool with the MotorCAD models, the details of which are presented in Table I. Machine 1 is a $25 \mathrm{~kW}$, concentrated wound machine with a base and maximum speed of $12.4 \mathrm{kRPM}$ and $20 \mathrm{kRPM}$ respectively. On the other hand, Machine 2 is a $51 \mathrm{~kW}$ distributed wound machine with a base and maximum speed of $14 \mathrm{kRPM}$ and $25 \mathrm{kRPM}$ respectively. The MotorCAD model of Machine 1 and 2 are shown in Fig. 3(a) and Fig. 3(b) respectively.

TABLE I. ELECTRICAL PARAMETERS OF CONSIDERED MACHINES

\begin{tabular}{l|c|c|c}
\hline \multicolumn{1}{c|}{ PARAMETERS } & $\begin{array}{c}\text { Machine 1 } \\
\mathbf{( 1 8 S / 1 2 P )}\end{array}$ & $\begin{array}{c}\text { Machine 2 } \\
\mathbf{( 3 6 S / 1 2 P )}\end{array}$ & UNIT \\
\hline Winding Configuration & Concentrated & Distributed & - \\
\hline DC-Link Voltage & 1080 & 1080 & $\mathrm{~V}$ \\
\hline Modulation Index & 0.9 & 0.944 & - \\
\hline Base Speed (Rated Speed) & 12 & 14 & $\mathrm{kRPM}$ \\
\hline Maximum Speed & 20 & 25 & $\mathrm{kRPM}$ \\
\hline d-axis Inductance & 0.68 & 0.34 & $\mathrm{mH}$ \\
\hline q-axis Inductance & 0.76 & 0.35 & $\mathrm{mH}$ \\
\hline Phase Resistance & 910 & 240 & $\mathrm{~m} \Omega$ \\
\hline No-load Flux Linakge & 66 & 60 & $\mathrm{mVs}$ \\
\hline Output Power & 25 & 51.5 & $\mathrm{~kW}$ \\
\hline Output Torque & 19.1 & 34.72 & $\mathrm{Nm}$ \\
\hline Phase Peak Current & 32.3 & 65.1 & $\mathrm{~A}$ \\
\hline \hline
\end{tabular}
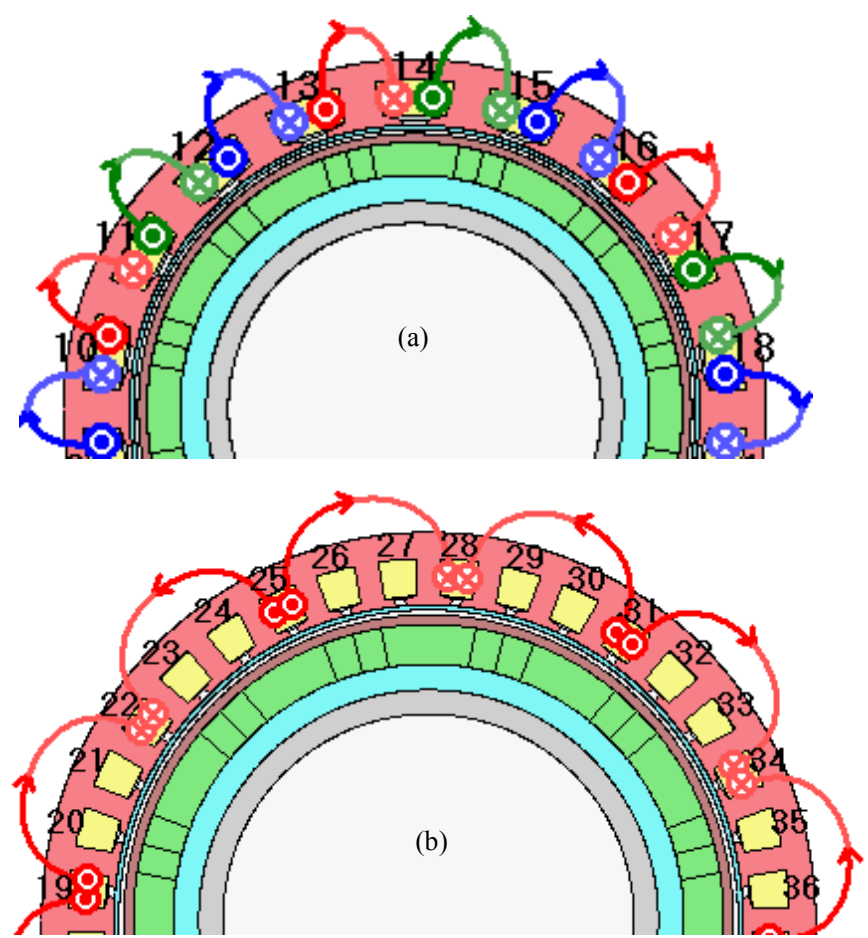

Fig. 2. MotorCAD Models (a) Machine 1 with the concentrated winding arrangement (b) Machine 2 with the distributed winding arrangement

\section{A. Effect of Stator Resistance Drop}

The effect of stator resistive voltage drop in the analytical tool is shown in Fig. 3(a)-(b) where d-axis current of Machines 1 and 2 is plotted against the rotor speed using (16) and (20). As expected, the values of d-axis current are negative for the initial values of the speed when the resistive drop is not considered as compared to the roots of (20), therefore, giving the wrong values of $\mathrm{d}$-axis current and hence wrong phase advance angles. To accurately predict the phase advance angles it is necessary to include the stator resistance in the analytical model even though it is quite small.
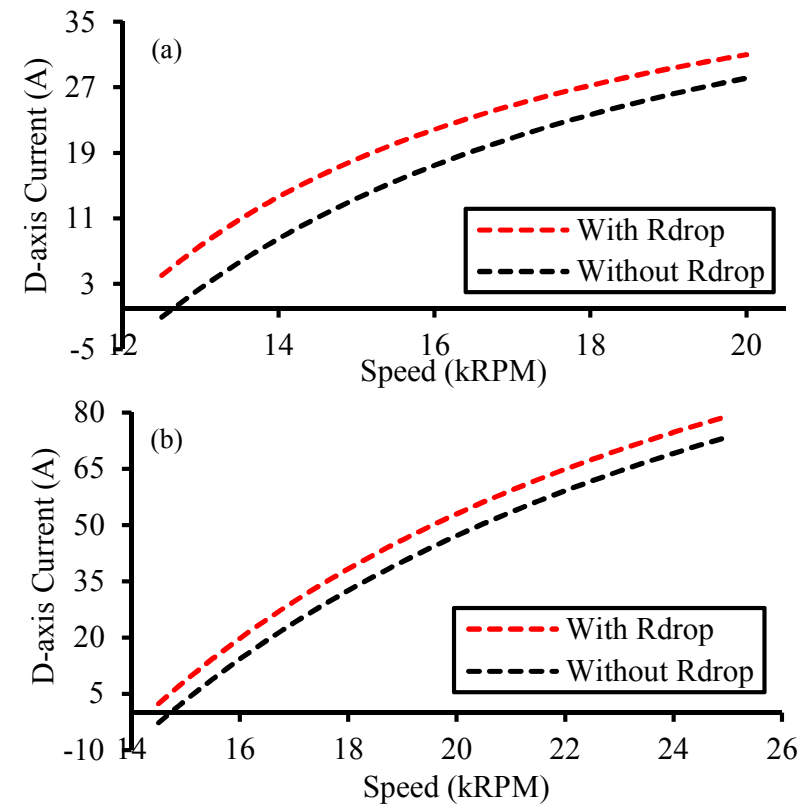

Fig. 3. D-axis Current vs speed curve (a) Machine 1 (b) Machine 2

\section{B. Comparison of Analytical Tool with MotorCAD}

The phase advance angle of the analytical model and MotorCAD software have been compared to see the effectiveness of the tool. Fig. 4(a) shows the phase advance angle vs speed curve of machine 1 when stator current is constant where d-axis current is evaluated using (27). The phase advance angle vs speed curve of machine 2 when the output power is held constant is shown in Fig. 3(b) where daxis current is evaluated using (20).
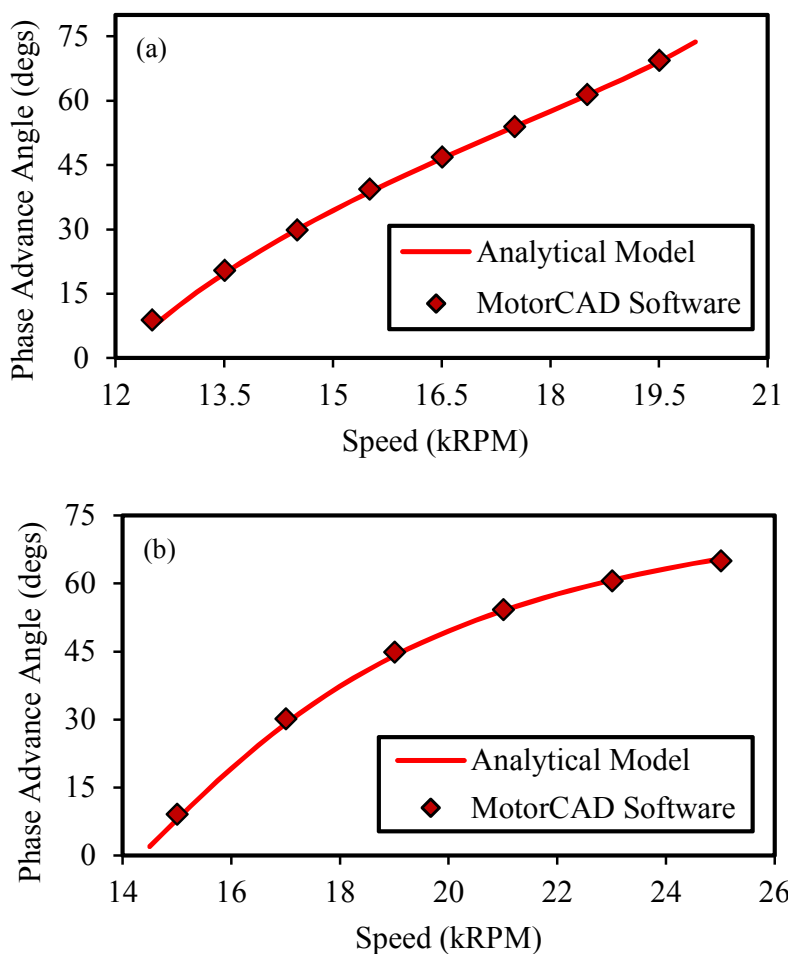

Fig. 4. Comparison of Phase Advance Angles (a) Machine 1 when stator current is constant (b) Machine 2 when the output power is constant 

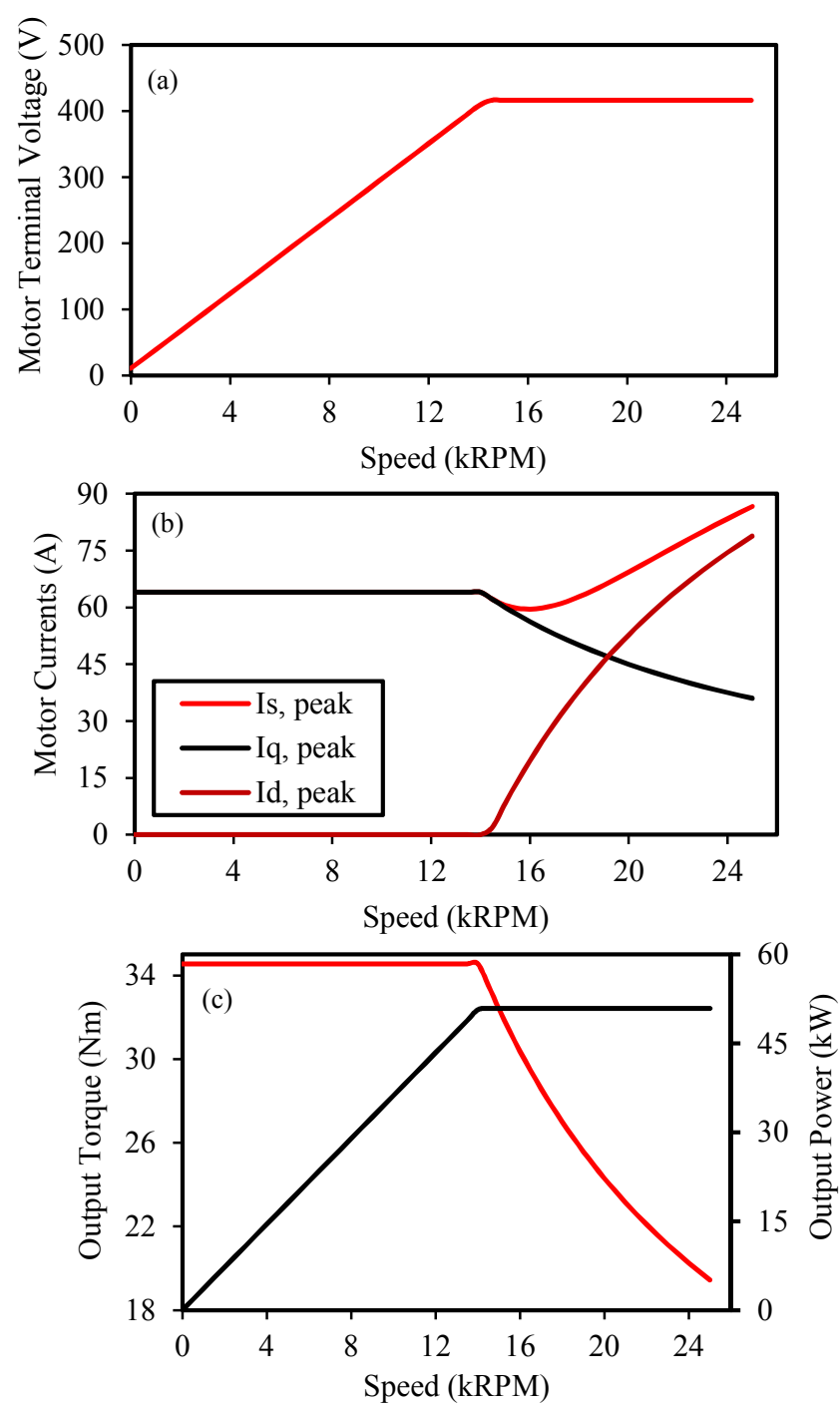

Fig. 5. Results of Analytical Tool of Machine 2 when Output Power is Constant (a) Torque and Power vs speed curves (b) stator current and d-q axis current vs speed curves (c) Phase RMS Motor Voltage vs speed curve
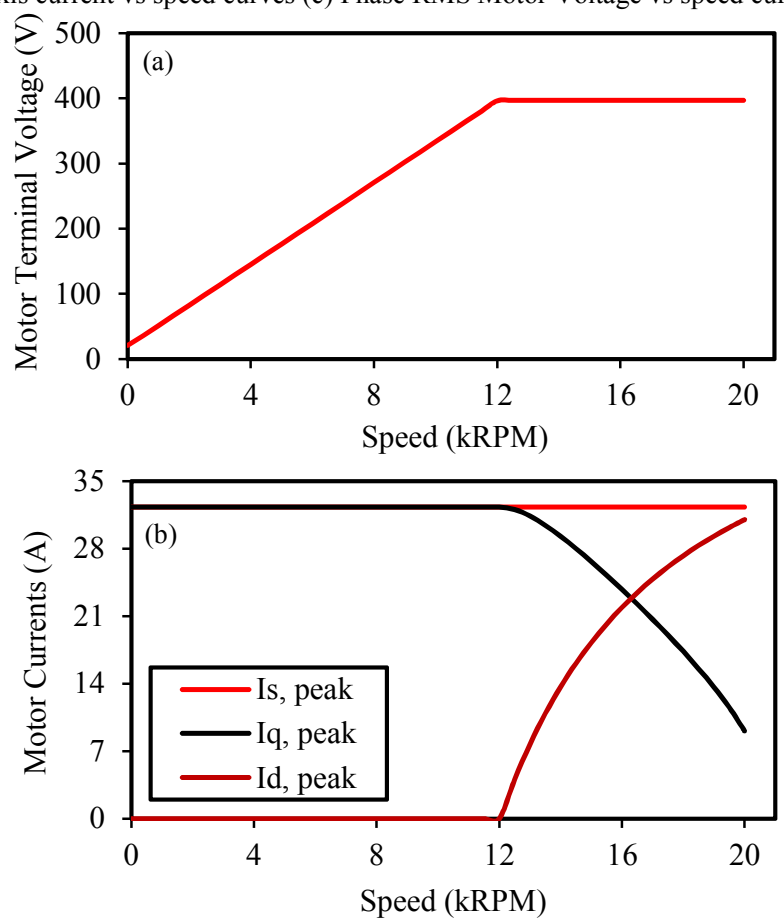

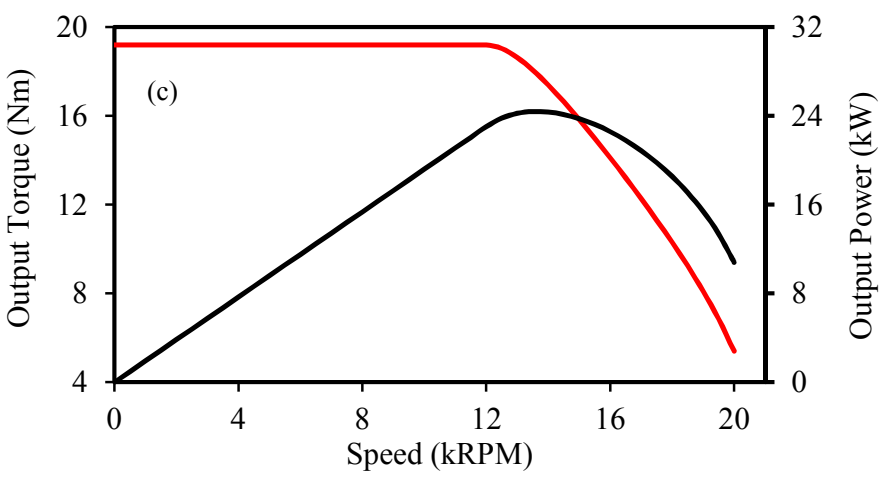

Fig. 6. Results of Analytical Tool of Machine 1 when Stator Current is Constant (a) Torque and Power vs speed curves (b) stator current and d-q axis current vs speed curves (c) Phase RMS Motor Voltage vs speed curve

It can be seen from Fig. 4 that the values of the analytical model are in a good agreement with the MotorCAD figures. The discrepancy of less than $1 \%$ is noticed due to the change in $\mathrm{d}-\mathrm{q}$ axis inductances in the MotorCAD software when the machine is operating in the field weakening region.

\section{Torque, Power, Current and Voltage vs Speed Curves}

The torque, power, current and voltage vs speed characteristic curves are presented in this section. The characteristic curves of the machine 1 are shown in Fig. 5(a) to Fig. 5(c) when stator current is remained constant in both constant torque and field weakening regions. Fig. 6(a) to Fig. $6(\mathrm{c})$ shows the characteristic curve of the machine 2 when the output power is held constant from the machine where stator current is increased in the field weakening region to meet the constant power requirement. In Fig. 5(a) and Fig. 6(a), motor voltage increases with respect to the rotor speed using (17) until it reaches to its rated value in the constant torque region. Once it has been reached to its rated value machine goes into the field weakening region where motor voltage is held constant to its maximum allowable voltage limit with modulation index take into account.

Fig. 5(b) and Fig. 6(b) shows the motor currents (stator current and $d q$ axis currents) of the machine 1 and machine 2 respectively. Fig. 4(b) shows the constant stator current which is given as an input whereas, Fig. 6(b) shows that the tool adjusted the stator current for the machine 2 to produce the constant output power in the field weakening region. Since the d-axis current increases using (20) and (27) q-axis current decreases in proportion in the field weakening region. As can be observed from Fig. 5(c) and Fig 6(c), the output torque is remained constant using (6) until motor's terminal voltages reach to its rated value and output power increases based on (7) as the rotor speed approaches to its base speed. In the field weakening region, output torque falls as the d-axis current increases and q-axis current decreases. The output torque is calculated based on the q-axis current evaluated from (9).

\section{CONCLUSION}

The analytical tool to generate torque, power, d-axis current vs speed profile has been presented in this paper. The papers derive an expression of d-axis current in the field weakening region for two cases: 1) when the output power from the machine is held constant in the field weakening region. For this case, the supply current is adjusted to meet the 
constant power requirement 2) when the output power from the machine is not constant. In this case, the supply current is held constant in the field weakening region. Subsequently, the phase advanced angle of the two machines was compared with the MotorCAD software to check the effectiveness of the analytical tool. The results of the analytical tool have made an excellent agreement with the motorCAD results with less than $1 \%$ of discrepancies. Finally, the results of the analytical tool for two machines have been discussed at the end.

\section{REFERENCES}

[1] A. Al-Timimy, P. Giangrande, M. Degano, Z. Xu, M. Galea, C. Gerada, G. Lo Calzo, H. Zheng, and L. Xia, "Design and Losses Analysis of a High Power Density Machine for Flooded Pump Applications" in IEEE Trans. On Industry Applications, vol. 54, no. 4, pp. 3260-3270, 2018.

[2] R. Islam, I. Husain, A. Fardoun, and K. McLaughlin, "PermanentMagnet Synchronous Motor Magnet Designs With Skewing for Torque Ripple and Cogging Torque Reduction," IEEE Transactions on Industry Applications, vol. 45, pp. 152-160, 2009.

[3] T. M. Jahns, G. B. Kliman, and T. W. Neumann, "Interior PermanentMagnet Synchronous Motors for Adjustable-Speed Drives," IEEE Transactions on Industry Applications, vol. IA-22, pp. 738-747, 1986.

[4] S. A. Odhano, R. Bojoi, Ş. G. Roşu, and A. Tenconi, "Identification of the Magnetic Model of Permanent-Magnet Synchronous Machines Using DC-Biased Low-Frequency AC Signal Injection," IEEE Transactions on Industry Applications, vol. 51, pp. 3208-3215, 2015.

[5] S. A. Odhano, P. Giangrande, R. I. Bojoi, and C. Gerada, "SelfCommissioning of Interior Permanent- Magnet Synchronous Motor
Drives With High-Frequency Current Injection," IEEE Transactions on Industry Applications, vol. 50, pp. 3295-3303, 2014.

[6] M. A. Rahman, "History of interior permanent magnet motors [History]," IEEE Industry Applications Magazine, 2013

[7] A. Al-Timimy, M. Alani, M. Degano, P. Giangrande, M. Galea, and C. Gerada, "Influence of Rotor Endcaps on the Electromagnetic Performance of High Speed PM Machine," in HYPERLINK "http://digital-library.theiet.org/content/journals/iet-epa" IET Electric Power Applications, Vol. 12, no. 8, pp 1142-1149, 2018.

[8] A. Al-Timimy, G. Vakil, M. Degano, P. Giangrande, C. Gerada, and M. Galea, "Considerations on the Effects that Core Material Machining has on an Electrical Machine's Performance", in IEEE Transaction on Energy Conversion, vol. 33, no. 3, pp. 1154-1163, 2018.

[9] Z. Huang, T. Yang, P. Giangrande, S. Chowdhury, M. Galea, and P. Wheeler, "An active modulation scheme to boost voltage utilization of the dual converter with a floating bridge," IEEE Transactions on Industrial Electronics, vol. 66, no. 7, pp. 5623-5633, 2019.

[10] A. Al-Timimy, M. Degano, Z. Xu, G. L. Calzo, P. Giangrande, M. Galea, et al., "Trade-off analysis and design of a high power density PM machine for flooded industrial pump," in IECON 2016 - 42nd Annual Conference of the IEEE Industrial Electronics Society, 2016

[11] A. Walker, M. Galea, C. Gerada, A. Mebarki, and D. Gerada, "Design considerations for high performance traction machines: Aiming for the FreedomCar 2020 targets," in 2015 International Conference on Electrical Systems for Aircraft, Railway, Ship Propulsion and Road Vehicles (ESARS), 2015, pp. 1-6.

[12] P. Giangrande, A. Galassini, S. Papadopoulos, A. Al-Timimy, G. Lo Calzo, M. Degano, C. Gerada and M Galea, "Considerations on the development of an electric drive for a secondary flight control electromechanical actuator," in press on IEEE Transactions on Industry Applications, DOI 10.1109/TIA.2019.2907231, pp. 1-1, 2019. 